\title{
CEOs' understanding of blockchain technology and its adoption in export-oriented companies in West Sweden: a survey
}

Viktor Elliot, Jonas Floden, Conny Overland and Zeeshan Raza Department of Business Administration, School of Business Economics and Law, University of Gothenburg, Goteborg, Sweden

Miroslaw Staron

Department of Computer Science and Engineering, University of Gothenburg, Goteborg, Sweden

Johan Woxenius

Department of Business Administration, School of Business Economics and Law, University of Gothenburg, Goteborg, Sweden

Abhinayan Basu and Trisha Rajput Department of Law, School of Business Economics and Law, University of Gothenburg, Goteborg, Sweden

Gerardo Schneider

Department of Computer Science and Engineering, University of Gothenburg, Goteborg, Sweden, and

Gunnar Stefansson

Department of Technology Management and Economics, Chalmers University of Technology, Gothenburg, Sweden

\footnotetext{
Abstract

Purpose - The purpose of this paper is to study current practices in adopting blockchain technology amongst export companies in West Sweden and to capture their CEOs' knowledge of and attitudes towards blockchains.

Design/methodology/approach - Factors enabling or hindering the adoption of blockchains were identified from a comprehensive literature review and a survey of 72 chief executive officers (CEOs) of export-oriented firms in West Sweden, all with turnovers exceeding $€ 2 \mathrm{~m}$, regarding their knowledge of and attitudes towards blockchains.
}

(C) Viktor Elliot, Jonas Floden, Conny Overland, Zeeshan Raza, Miroslaw Staron, Johan Woxenius, Abhinayan Basu, Trisha Rajput, Gerardo Schneider and Gunnar Stefansson. Published by Emerald Publishing Limited. This article is published under the Creative Commons Attribution (CC BY 4.0) licence. Anyone may reproduce, distribute, translate and create derivative works of this article (for both commercial and non-commercial purposes), subject to full attribution to the original publication and authors. The full terms of this licence may be seen at http://creativecommons.org/licences/by/4.0/legalcode

Understanding of blockchain technology

Received 21 July 2020 Revised 20 December 2020 Accepted 28 January 2021 
Findings - Blockchain technology is not currently perceived to provide benefits that would outweigh the costs of introducing it into West Sweden's export firms. Nevertheless, the findings suggest that such technology, though currently too immature to meet today's industrial requirements, could experience more widespread use if certain key factors (i.e. lower cost, traceability, improved security or trustworthiness and new blockchain-enabled business models) are prioritised.

Research limitations/implications - Answered by 72 CEOs, the survey achieved a response rate of $6 \%$, meaning that the findings are only exploratory. Even so, they offer new insights into CEOs' attitudes towards blockchain technology.

Practical implications - The CEOs reported comparatively limited knowledge of and experience with implementing blockchains, the lack of which has hampered their large-scale implementation in multi-actor supply chains.

Social implications - Negative sentiment amongst CEOs towards blockchain technology may lower onthe-job satisfaction amongst tech personnel aspiring to develop and implement blockchain applications in their firms.

Originality/value - Knowledge of and attitudes towards blockchain technology amongst top-level managers, as well as about factors enabling or hindering its adoption, guide managers in crafting strategies for implementing blockchains in their organisations and maximising the benefits therein. Unlike past studies focussing on technological aspects or views of experts and middle-management, the study was designed to capture the views of CEOs.

Keywords Adoption, Survey, CEO, Blockchain, Both, BCT, Attitude, Chief executive officer, Implementation, Manager, Supply chain management

Paper type Research paper

\section{Introduction}

Blockchain technology (BCT) supports transparency, security and flexibility in informationsharing amongst multiple actors in various supply chains (Francisco and Swanson, 2018). BCT's simple underlying technical solutions combined with modern cryptography provide ready platforms for developing digitalised, distributed databases to replace current centralised solutions (Dhillon et al., 2017). In BCT, the distribution of information promotes trust in the quality and correctness of that information without requiring trusted agents to manage centralised databases (Gupta, 2018). Cryptography-intensive protocols for adding new information that prohibit modifying information currently in the blockchain (BC), provide the security needed in supply chains (SCs), financial transactions, energy distribution (Hwang et al., 2017) and even clinical records (Benchoufi et al., 2017). One of the most prominent uses of BCT today is the digital currency Bitcoin (Crosby et al., 2016; Yaga et al., 2019).

Although BCT has been adopted in finance and data exchange, it remains in its infancy in supply chain management (SCM) and transport. As Büyüközkan and Göçer (2018) have shown, today's SCs generally embrace some forms of digital technology due to their potential to enhance the speed, intelligence, transparency and scalability of SC operations. Nevertheless, several factors hinder the adoption of digital SCs, including their limited integration with non-digital SCs and the lack of collaboration between actors in the SCs. Although Büyüközkan and Göçer did not mention BCT by name, the challenges identified indicate that BCT could be a promising technology for more efficient SCM, even if others, including Sternberg et al. (2020), have observed multiple obstacles that continue to stifle the implementation of BCT. In support, Korpela et al. (2017) have identified SC processes in which BCT could theoretically be used - for instance, in defining data models, processing smart contracts and maintaining electronic ledgers. Because the complexity of managing SCs intensifies as they expand and add actors, international SCs face particular pressure from the added complexity of different legal requirements, longer transport distances and 
diverse business cultures, amongst other factors. Such trends can strain access to highquality data, which enables stakeholders in SCs to make more informed, proactive decisions that improve the performance of their SCs, as literature addressing SCM has firmly established (Christopher, 2011). After all, SCs today, especially long ones, often lack visibility and transparency, which forces actors therein to make decisions based on limited, narrow data, usually at the expense of the SC's efficiency (Heutger and Kückelhaus, 2018). Such obstacles could be overcome, however, by taking advantage of BCT (Ko et al., 2018; Kshetri, 2018) and its potential to boost transparency, traceability and security (Benton et al., 2018).

At the same time, the benefits of BCT come with a price: The computing power needed to create the cryptographic keys grows exponentially with the level of security needed. Although developing a basic $\mathrm{BC}$ solution is relatively simple, developing one that is secure and scales up to multiple agents, as is necessary with $\mathrm{SCs}$, can be quite costly. Beyond that, whether using BCT is even practical on such large scales continues to be debated (Wüst and Gervais, 2018). Even if so because current SCs have already been developed and are already functioning, the cost of introducing new solutions or integrating them with existing ones can be prohibitive.

Despite those setbacks, popular media and literature addressing SCM, including Madir (2000), Saveen and Radmehr (2016) and Feng (2017), increasingly showcase BC-based solutions that have been proposed or even developed, some for materials and consumables. In those cases, the solutions typically focus on four key properties: the material's nature (i.e. what it is), quality (i.e. how it is), quantity (i.e. how much of it there is) and ownership (i.e. whose it is at any moment). Because a BC consists of a set of recorded data distributed within a computer network where each participant (or "node") holds the (identical) set of records, the data held can be static (e.g. as in databases), dynamic (e.g. as on trading platforms) or executable (e.g. as in smart contracts). In that context, a smart contract is an agreement made automatable by computer, although some parts may require human input and control and enforceable by either the legal enforcement of rights and obligations or the tamper-proof execution of computer code (Madir, 2000; Morabito, 2017; Ryan, 2017).

Given the hype surrounding BCT, it is important to understand the potential benefits and key challenges associated with its adoption. Research on BC applications in logistics and SCM remains underdeveloped, however, and knowledge regarding its adoption in such organisations is, therefore, limited (Wamba and Queiroz, 2020). In a bid to counter that deficit, we set out to investigate whether $\mathrm{BCT}$ is regarded as a viable alternative for $\mathrm{SC}$ in export-oriented industries. To that end, the following research question is formulated:

Q1. To what extent has blockchain technology been adopted in West Sweden's exportoriented industry and how is the technology understood by the industry's Chief Executive Officers?

We conducted our study in Sweden, recognised by the OECD (2018) and Gürdür et al. (2019), amongst others, as a leader in digital infrastructure and digital innovation. Data collection targeted West Sweden, especially the highly trade-focussed Västra Götaland County, home to some 1.7 million citizens, which we deemed to have a scope relevant to studying BCT in SCM. To collect data, we designed a survey about the adoption of BCT and Chief Executive Officers (CEOs)' understanding of the technology, which we distributed to export-oriented companies throughout West Sweden. The West Sweden Chamber of Commerce (WSCC) assisted with distributing the survey to the CEOs of member firms that met our criteria.

As a result of our study, this article focussed on clarifying top-level management's understanding of and attitudes towards BCT fills a gap in literature that largely focusses on
Understanding of blockchain technology 
the technical aspects of BCT (Risius, 2017) and potential uses (Casino et al., 2019; Queiroz et al., 2019; Wang et al., 2019a). Although barriers to its implementation have been investigated, such studies have previously not taken the perspective of top-level management. As other studies have shown, initiatives for cultivating innovations and developing new products and/or services require top-level management's support to succeed (Fui-Hoon Nah et al., 2001; Oke, 2004) and applying BCT is no exception (Bag et al., 2020). Against that background, we strove to pinpoint the degree to which actions to adopt and implement BCT are anchored in company strategy and central decision-making overseen by top-level managers - namely, CEOs.

To identify previous research on the topic, we conducted a literature search in Scopus with the keywords "blockchain" and "survey" and "management" or "president" or "CEO" or "top management" or "executive" in the article title, abstract or keywords. The search returned 181 articles, which we screened for their titles and abstracts. Ultimately, we selected 15 articles to read in detail for further analysis.

While most studies have targeted experts in either BCT or a specific field (e.g. logistics), none have actively pursued the perspective of top-level managers and the ones that have involved "managers" have rarely reported their level of management. Amongst the exceptions, Saberi et al. (2019a) reported that $9 \%$ of their respondents were "upper level" management, while Durach et al. (2020) reported that $62 \%$ of theirs were "executive managers". To be included in our review, articles needed to expressly state that at least $50 \%$ of the respondents were top-level management (e.g. "top-level managers" or "CEOs"). Although three articles addressed the perceptions of top-level management (Table 1), none purposely considered their perspectives. Thus, this article partly fills a gap in the literature by capturing CEOs' knowledge of BCT and their attitudes towards adopting it at their organisations.

The remainder of this article is organised as follows. In Section 2, we review the literature addressing the potential value of BCT and its current applications, after which we summarise major challenges in adopting and implementing BCT in Section 3. Next, we describe our study's methodology in Section 4 and present our results in Section 5. In Section 6 , we discuss our principal findings in relation to the literature, after which we articulate our conclusions in Section 7.

\section{Blockchain technology: applications and advantages}

Viewing BC-based applications in SCM from a theoretical perspective, several recent review articles - for example, by Queiroz et al. (2019) and Wang et al. (2019a) - have covered the extensive publication of findings about BCs and BCT in general. In particular, Queiroz et al. (2019) revealed that BCT, despite its vast potential, has an overall low rate of adoption across sectors, with the notable outlier of the energy sector, owing to its widespread use of smart contracts.

Beyond that, however, the scope of research on adopting BCT has been rather limited. In work performed in the past three years, van Hoek (2019a) examined three companies, one in logistics, that conducted a pilot implementation of a $\mathrm{BC}$ solution. Although the trial's results demonstrated the promise of the technology, the solution never progressed beyond the pilot projects. Along similar lines, Dobrovnik et al. (2018) observed the massive potential for BCT's adoption, which was nevertheless often stymied by a lack of knowledge and empirical data (e.g. from use cases and case scenarios). Petersen et al. (2018) and Sternberg et al. (2020) published results in the same direction, as did Gausdal et al. (2018); all of their studies involved interviews in Norway's maritime industry. Prasad et al. (2018), by contrast, conducted a literature review that yielded 19 factors identified as driving the successful 


\begin{tabular}{|c|c|c|c|}
\hline Study & Purpose and method & Findings & \\
\hline Durach et al. (2020) & $\begin{array}{l}\text { Studied the adoption of BCT in SCM } \\
\text { with a survey of managers in Germany, } \\
62 \% \text { of whom were executive } \\
\text { managers and not separated in the } \\
\text { analysis }\end{array}$ & $\begin{array}{l}\text { The authors identified } 13 \text { areas in SCM } \\
\text { in which BCT could be applied, ranked } \\
\text { by likelihood of adoption, time frame } \\
\text { and business impact. Respondents } \\
\text { considered the areas to likely have BCT } \\
\text { but not in the near future }\end{array}$ & \\
\hline Zhou et al. (2020) & $\begin{array}{l}\text { Examined factors of BCT's success in } \\
\text { Singapore's maritime industry with a } \\
\text { survey of } 30 \text { respondents, } 29 \text { of whom } \\
\text { were top-level managers }\end{array}$ & $\begin{array}{l}\text { The authors identified six critical } \\
\text { factors for BCT's success, of which lack } \\
\text { of capital is the largest obstacle, } \\
\text { followed by staff training and } \\
\text { legislation }\end{array}$ & \\
\hline Yang (2019) & $\begin{array}{l}\text { Gauged the possible use of BCT in } \\
\text { maritime SCM in Taiwan's shipping } \\
\text { industry with a survey of } 121 \\
\text { respondents, } 55 \% \text { of whom were vice- } \\
\text { presidents or directors, if not higher }\end{array}$ & $\begin{array}{l}\text { Despite promising applications in } \\
\text { customs clearance and management, } \\
\text { the digitalisation of paperwork and } \\
\text { standardising and developing } \\
\text { platforms, respondents in higher } \\
\text { positions had less intention to use BCT }\end{array}$ & $\begin{array}{r}\text { Table } 1 . \\
\text { Summary of studies } \\
\text { on BCT involving } \\
\text { top-level managers in } \\
\text { supply chain } \\
\text { management (SCM) }\end{array}$ \\
\hline
\end{tabular}

adoption of BCT. By extension, they stressed that to sustain the success of BC-based services, industrial and technological efforts should prioritise improving regulatory clarity, driving industry collaboration, building a rich ecosystem, developing industry standards, investing in BCT and engaging and educating leaders about BCs' capability and applications. Similarly, Hoxha and Sadiku (2019) identified transparency, security and cost reduction in real estate transactions as important drivers for BCT's adoption in Kosovo. More recently, Ghode et al. (2020a, 2020b), drawing from a literature review and interviews with five $\mathrm{BC}$ experts, ranked inter-organisational trust, relational governance, interoperability, data transparency, data immutability and behavioural intention amongst the key challenges hindering the adoption of BCT.

In other work, van Hoek (2019b) held a workshop with senior executives who discussed adopting $\mathrm{BCT}$ in the logistics sector. Despite revealing a low rate of adoption and a lack of business cases, as well as competence, the workshop also showed that the major drivers of adoption were improving security and process visibility. Conversely, the biggest impediments to the adoption of BCT were its integration with the current processes and an unknown cost-benefit ratio. Offering a rosier outlook, Morkunas et al. (2019) demonstrated BCT's potential to benefit companies' business models, customer relations, distribution channels and similar elements of business development. In the same vein, Sheel and Nath (2019), who conducted a survey amongst Indian SC managers, determined that adopting $\mathrm{BCT}$ can give firms the competitive advantage of agility, particularly by reducing manufacturing lead times, improving the frequency of new product development, expanding delivery capabilities and increasing customer satisfaction. On top of that, they found that adopting BCT can boost the reliability of transactions and, in turn, increase transparency, especially by supplying a tamper-proof source of data recording and retrieval that better enables firms to track inventory items. Needless to say, all of those attributes of BCT can enhance firms' performance. By extension, Boukis (2019), who considered the implications of adopting BCT for brands and consumers, found that adoption can help brands to become more authentic, transparent and trustworthy and, as a result, acquire new customers and improve brand image. 
To exploit benefits offered by $\mathrm{BCT}$, a range of $\mathrm{BC}$-based initiatives have been taken across sectors, including shipping, food and retail, pharmaceuticals and even diamonds and luxury products (Queiroz et al., 2019). For a better understanding of recent developments in the field, Table 2 summarises blockchain initiatives that have been undertaken in various industries to date.

As demonstrated by the initiatives described in Table 2, SCs for crucial goods, including foods and pharmaceutical products and luxury goods such as diamonds, have become hotspots for BC-based initiatives due to the urgent need for reliable traceability and product provenance. Knowing the origin and the footprint of products as they have travelled throughout SCs offers not only commercial benefits, including improved legitimacy and consumer confidence in brands but can also enhance safety, as in the enhanced traceability of medicine and foods (Wang et al., 2019a) and the obstructed distribution of so-called "blood diamonds".

\section{Challenges in adopting blockchain technology}

Despite the numerous applications and advantages of BCs identified in the literature, the adoption of BCT confronts various technological, organisational, governance, operational, legal and policy-related challenges (Saberi et al., 2019b; Wang et al., 2019a). For that reason, organisations contemplating adopting BCT need to consider several factors to make informed decisions about whether to proceed with adoption.

Although the decentralised, distributed characteristics of BCs make them highly resilient compared with traditional databases, the secure use of $\mathrm{BCs}$ continues to be a major challenge (Wang et al., 2019b). Particularly notorious are the gaps in security in BCT applied to cryptocurrencies, in terms of both guarantees and vulnerabilities (Lim et al., 2014). According to Patel et al. (2017) because hacking into a public (permission-less) BC requires significant financial and computational power, a permission $\mathrm{BC}$ may be more vulnerable to cyberattack. To overcome such weaknesses, different solutions have been proposed, though their efficacy has yet to be evaluated (Yli-Huumo et al., 2016). In the meantime, it remains critical to identify potential security problems for the application specifically targeted by the organisation.

As a relatively immature technology, BCT is considered to have an underdeveloped capacity for scalability and handling large volumes of transactions (Croman et al., 2016; YliHuumo et al., 2016). For example, compared with payment processors such as Visa that can process an average of 2,000 transactions per second (tps) at peaks of 56,000 tps, public BCs such as Bitcoin's network process approximately 7 tps on average (Croman et al., 2016; Ganne, 2018). As a consequence, increased rates of BC transactions can create congestion and cause delays in the validation of transactions. However, against that trend, Hyperledger Fabric, a distributed operations system behind permissioned BCs, can process up to 3,500 tps (Androulaki et al., 2018). Clearly, permissioned BCs typically used in international trade do not face the same restricted scalability as public BCs do (Ganne, 2018). For that reason, it is essential for businesses and other BC stakeholders to consider their scalability-related needs to maintain the efficiency and relevance of their BC-based systems over time.

Amongst other challenges for organisations interested in implementing BC-based solutions, Mougayarm (2016) has identified the lack of technical expertise, knowledge and understanding about business models and best practices in successfully implementing those solutions. To be sure, adopting BC-based solutions can imply designing an entirely new IT solution and the corresponding process of overhauling part, if not all, of the current system. Because the endeavour can require new roles, responsibilities and expertise to support different facets of BCT's implementation in the organisation (Wang et al., 2019a), 


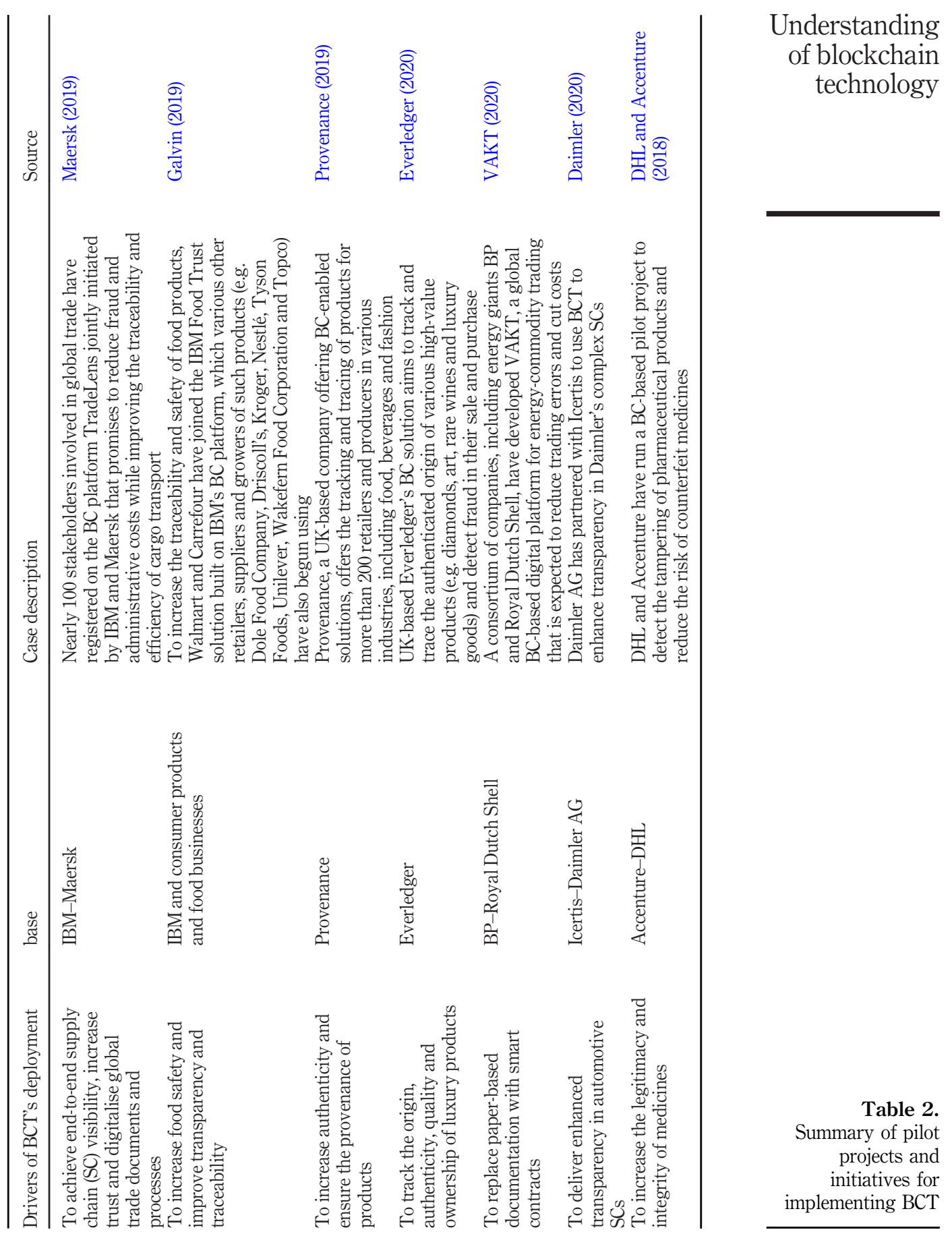


organisational culture is necessarily affected and resistance from management is not uncommon (Wang et al., 2017). Outside the organisation, institutional actors such as banks and other SC intermediaries that economically benefit from existing systems may regard $\mathrm{BCT}$ as a threat to their revenue streams, and thus refuse to coordinate BC-based transactions (Michelman, 2017; Zhao et al., 2016).

At the same time, even if $\mathrm{BCT}$ is an important technology for the market, organisations may have priorities other than adopting it. In such cases, organisations need to be provided with additional resources to develop an interest in BCs. Adopting BC-based solutions requires financial, human and logistical resources to conduct feasibility studies and invest in related software and hardware, which can be difficult for firms facing financial straits. In particular, small and medium-sized companies may struggle to join BC platforms due to the financial cost (Tapscott and Tapscott, 2016; Wang et al., 2017). For example, Haraldson et al. (2020) have illustrated how smaller ports can play pivotal roles in transport chains but possess limited resources for fulfilling larger firms' expectations of connecting electronically to various administrative systems.

Although transparency and verifiability are important for improving the performance of $\mathrm{SC}$, some organisations remain unwilling to disseminate their business information over $\mathrm{BC}$ platforms (Kembro et al., 2014). After all, the open nature of the platforms does not necessarily prevent sensitive information from leaking to competitors (Saberi et al., 2019b). In that light, a reluctance to reveal critical information with other partners in an SC may hinder the implementation of BCT across the entire chain. At the same time, privacy in the context of BCs remains poorly understood and organisations may fear potential leaks simply because information about the built-in privacy designs and backup mechanisms is limited. According to Krombholz et al. (2017), concerns with data privacy can pose implications for governance. If electronic health-care records, for instance, are entered into a $\mathrm{BC}$ network, then the users face severe consequences if those records are breached. Thus, to control the governance of data and compliance, location privacy should be ensured for all users (Biswas and Gupta, 2019).

Despite the many studies and initiatives on BCs and BCT, their successful commercial implementations have been few (Queiroz et al., 2019; Sternberg et al., 2020). In global SCs, the successful implementation of BCT requires collaboration amongst all stakeholders, who may be based in various locations, and hence subject to different jurisdictions and, as Casey and Wong (2017) have indicated, the complexity of diverse operating environments can easily hinder the smooth implementation of $\mathrm{BCT}$ in $\mathrm{SC}$ processes.

Although $\mathrm{BCs}$ are tamper-resistant, decentralised, distributed digital records of transactions that engender trust precisely because of those characteristics, they do not always accurately reflect the movement of materials in SCs or prevent false information from entering the system (Apte and Petrovsky, 2016). In fact, BCs are vulnerable to contingent errors, conflicts of interest, corruption and malicious attacks (Boucher et al., 2017).

The incompatibility and lack of interoperability of different $\mathrm{BCs}$ are other practical deterrents to their use. Currently, to satisfy the specific needs of different industries, different $\mathrm{BC}$ systems have been developed with different technical interfaces and algorithms and, as a consequence, cannot communicate with each other. For example, systems launched by IBM and Everledger are built on Hyperledger Fabric, whereas Microsoft and Provenance - the start-up offering BC-based solutions to track products and enhance SC transparency - use Ethereum (Wang et al., 2019b). Although each BC is independently of interest, the incompatibility and/or lack of interoperability between them can restrict the scalability and use of their platforms. Thus, the chief goal of using $\mathrm{BC}$ - in short, to integrate 
processes in transparent, dynamic ways - becomes impossible, particularly in international trade, in which an international shipment can impact a dozen different ledgers. For seamless data transfer, the interoperability of different BCs needs to be improved (Collomb and Sok, 2016; Ganne, 2018; Wang et al., 2017).

For yet another shortcoming, BCs have been criticised for the high level of energy needed to operate the networks (Ganne, 2018). While environmental concerns currently top the global policy agenda, the increased use of $\mathrm{BCs}$ can harm the environment by increasing $\mathrm{CO}_{2}$ emissions.

Specific legal regulations concerning $\mathrm{BC}$ - for example, about which information can be publicly available - may also be unclear, including those regarding the use of BCT. Contradictions in policies issued by different governments about Bitcoin have raised concerns amongst organisations and markets around the world, which can affect the broader use of BCs amongst businesses and SC networks (Mougayarm, 2016). Taxation rules are especially unclear for $\mathrm{BC}$-enabled transactions paid with cryptocurrencies and, to date, governments have struggled to impose monetary policy concerning BCs and tax the income or value-added services offered under BC-based transactions (Akins et al., 2015).

Due to the independent nature of $\mathrm{BCs}$, aspects of IT governance such as decision-making rights, accountability and incentives can also affect applicable laws (Beck et al., 2018). For instance, firms using $\mathrm{BC}$ networks are not required to comply with data privacy laws such as the US Federal Information Security Management Act of 2002 and the General Data Protection Regulation 2018 in the European Union. As a consequence, businesses being built on $\mathrm{BC}$ platforms may face new regulatory challenges once country-wide regulations are adopted (Beck et al., 2018; Grant and Hogan, 2015). In the case of global SCs, their massive scale and geographical spread have increasingly rendered them opaque to regulators and law enforcement agencies across jurisdictions have found it difficult to implement laws concerning, for example, counterfeit goods, forced labour, poor working conditions and connections to criminal activities. Internationally, lawmakers have sought solutions that could increase the visibility of SCs and, to that purpose, many believe that BCs and other distributed ledger technologies may be valuable.

Dealing with BCT and smart contracts entails a host of legal issues related to immutability - for instance, dealing with changes, hacks, unforeseen circumstances and renegotiations - that act as a double-edged sword (Cooper and Nash, 2000). Even so, in global SCs, more generic legal issues pose even greater challenges to the use of BCs. Businesses in such SCs that trade across borders have to navigate shipping regulations, embargo laws and regulations, export sanctions, anti-corruption and foreign corrupt practices laws, anti-money laundering requirements, anti-boycott laws and trade remedy regulations. Implementing $\mathrm{BC}$-based solutions by using smart contracts in international $\mathrm{SCs}$, therefore, requires careful consideration of jurisdiction-specific laws that apply to SC actors as a means to ensure that relevant regulatory obligations are met (UN-ECE, 2019). Table 3 summarises the various challenges that hinder the adoption of BCs and BCT.

From earlier studies, we identified four particularly important areas to understanding firms' willingness to adopt BCT. Firstly, any successful adoption of BCT requires knowledge and understanding of $B C T$ and several studies have likewise pinpointed lack of knowledge as an important obstacle to adopting BCT (Dobrovnik et al., 2018; van Hoek, 2019b).

Secondly, implementing BCT requires a sense of BCT's importance for future value creation. Projects motivated by $\mathrm{BCs}$ have, thus, been important in addressing specific challenges to, for example, ensuring the quality and origin of diamonds (Hackius and Petersen, 2017), increasing food safety (Galvin, 2019) and replacing paper-based documentation with smart contracts (Khatri, 2018). Even so, the lack of convincing cases of
Understanding of blockchain technology 
JGOSS

Table 3.

Summary of

challenges in

adopting $\mathrm{BC}$ and BCT

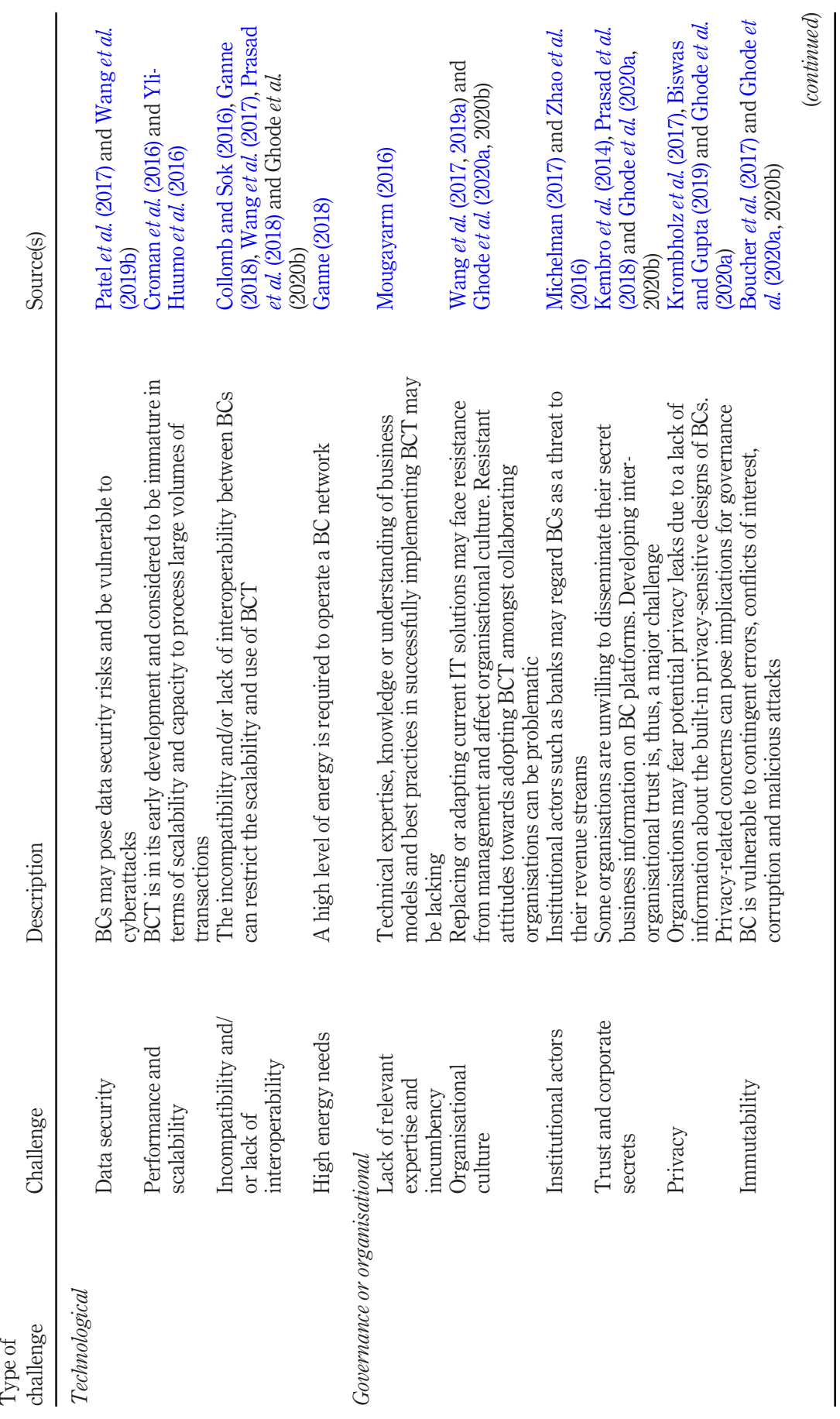




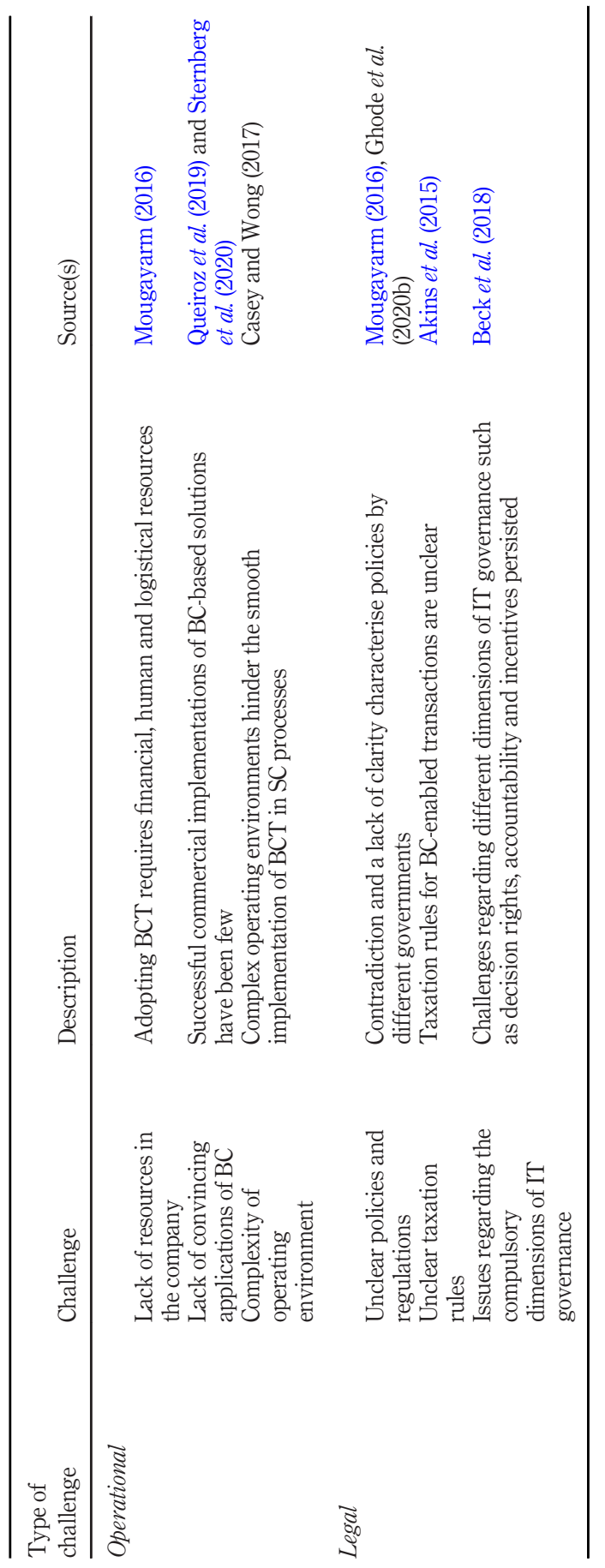

Understanding of blockchain technology 
BCT's implementation in commercial settings continues to impede its implementation in general (van Hoek (2019b).

Thirdly, factors that cause companies to introduce BCT is a major theme across the literature, which largely suggests that companies pursue BC-based solutions to lower costs (Hoxha and Sadiku, 2019; Khatri, 2018; Prasad et al., 2018; Wang et al., 2019b), reduce risk (DHL and Accenture, 2018), increase traceability and transparency in the value chain (Thomasson, 2019), increase speed (Galvin, 2019; McKenzie, 2018) and identify new business models or sources of income (Morkunas et al., 2019).

Fourthly and finally, the literature is concerned with factors that prevent companies from introducing BCT. Such factors include a lack of relevant organisational competence (Dobrovnik et al., 2018; Ghode et al., 2020a, 2020b, Mougayarm, 2016; Petersen et al., 2018; Sternberg et al., 2020) or resources (Haraldson et al., 2020; Tapscott and Tapscott, 2016; Wang et al., 2017), a shortage of applications or business cases (Prasad et al., 2018), legal obstacles (Prasad et al., 2018), security risks or potential information leaks (Ghode et al., 2020a, 2020b, Lim et al., 2014; Saberi et al., 2019a, Yli-Huumo et al., 2016), technological uncertainty (Croman et al., 2016; Yli-Huumo et al., 2016) and problems with implementation when replacing or adapting systems already in place (Ghode et al., 2020a, 2020b, Wang et al., 2017; Wang et al., 2019a).

Although all four of those topics have been addressed by studying particular cases or settings in which BCT has been piloted, less attention has been given to how top-level managers view $\mathrm{BCs}$ in general and perceive the advantages and obstacles of implementing $\mathrm{BCT}$.

\section{Design of the survey}

Our research question (i.e. To what extent has BCT been adopted in West Sweden's exportoriented industry and how is the technology understood by the industry's CEOs?) stems from the current lack of results about whether industrial firms use BCT to any degree and, if so, then why and how. We addressed that question by conducting a survey reflecting the four abovementioned areas related to the organisational adoption of BCT identified in the literature:

- knowledge and understanding of BCT,

- a sense of BCT's importance for future value creation,

- factors that cause companies to introduce BCT and

- factors that prevent companies from introducing BCT.

The lack of research encouraged us to adopt an exploratory survey methodology (Åhlström and Westbrook (1999) that emphasises descriptive results. For a setting, we chose Sweden, considered to be a forerunner in adopting digital technologies (Gürdür et al., 2019; OECD, 2018), one with a very high rate of digitalisation. This makes it a potentially critical case as a forerunner in the field.

We conducted the online survey in collaboration with the WSCC in April 2019. The survey was emailed by the WSCC, with the University of Gothenburg and Chalmers University of Technology named alongside WSCC as senders, to 1,393 Swedish exportoriented companies with an annual turnover of more than $20 \mathrm{~m}$ SEK (approximately $€ 2 \mathrm{~m}$ ) [1] or about $45 \%$ of the WSCC's approximately 3,000 members. The mailing list targeting the CEOs of WSCC members is normally used by the WSCC to distribute information and newsletters, amongst other things. The sample was selected because:

- it was relevant to our research topic, 
- cooperation with the WSCC implied a direct channel to the CEOs of a large number of firms in our target group and

- an email from the WSCC was expected to generate a better response rate.

Understanding of blockchain technology

The approach of using the member lists of industrial organisations has also been used by Saberi et al. (2019a), amongst other authors.

Of the 1,393 surveys distributed, 72 were returned, for a response rate of $5.2 \%$. Because research on $\mathrm{BCs}$ has only recently begun to emerge, studies on the topic have endured fairly low response rates - for example, Queiroz et al. (2019) achieved a response rate of only 6\% amongst US professionals, despite utilising a leading market research provider. Another factor was that the survey was distributed to a general email list of CEOs with substantial time constraints and addressed a narrow, rather technical field. Our comparison of early and late respondents indicated a slight difference but largely consistent results. The earliest 15\% and last $15 \%$ of respondents were compared regarding their answers to questions concerning their understanding and perception of BCs (Tables 5-7) and the median difference (absolute value) was only 0.43 ( $\max 1.2$, min 0.0$)$.

All respondents were CEOs or equivalent (e.g. president or owner) and came from a broad spectrum of industries (Table 4). The median number of employees at their firms was 37 , ranging from five to 24,000 employees and the firms had a median annual turnover of $€ 6.1 \mathrm{~m}$, ranging from $€ 1.4$ to $€ 1,130 \mathrm{~m}$.

Due to the survey's exploratory nature and considering the time constraints of the targeted managers, we kept the survey brief. It was divided into three parts and written in Swedish (see the Appendix for an English translation). The first part consisted of general questions about the respondent, the corresponding firm and their overall understanding of BCT. Next, the second part consisted of questions addressing the respondent's personal experience with BCT, after which the third part contained questions about the respondent's experience with working with $\mathrm{BCT}$ within their firm. The questions were based on literature addressing BCT and our experience with the topic. For most questions, the response options were designed as five-point Likert scales along with the option "I don't know".

Although the survey admittedly suffered from a low response rate, that result in itself could be interpreted to indicate that few companies currently use BCT. A non-response bias analysis made comparing early and late respondents showed no major difference in their BCT-related knowledge or experience. Another risk was that companies interested in BCT were more likely to answer the survey than others. Nevertheless, those limitations should be viewed in light of considerable interest in $\mathrm{BCT}$ and the near-complete lack of empirical evidence on the topic. In any case because the few studies that have been conducted

\begin{tabular}{lcc}
\hline Industry & Share of respondents (\%) \\
\hline Manufacturing & 25 \\
Construction & 19 \\
Retail and trade & 15 \\
Other & 11 & \\
IT & 8 & \\
Transport & 7 & Table 4. \\
Life sciences & 4 & Respondents by \\
Tourism and events & 4 & industry \\
Finance & 3 & 3 \\
Marketing and communications & 3 & \\
\hline
\end{tabular}


represent case-based, mostly prescriptive research, more systematic data collection has been needed and our survey was an early attempt in that direction.

\section{Results}

Revealing a general openness to and curiosity about BCs and BCT, the results of the survey highlighted that respondents believed that BCT would heavily impact their industry. At the same time, they admitted that their general level of understanding about BCT was quite low, very few companies had any projects regarding BCT and the understanding of how BCT could be used in their own organisations was low (Table 5).

The average reported understanding of $\mathrm{BCs}$ was strikingly low. Although $79 \%$ of respondents had heard the word "blockchain" before, only $57 \%$ claimed to know what one was. Furthermore, only $11 \%$ of respondents claimed to be knowledgeable or very knowledgeable about the topic. Similarly, $78 \%$ claimed to have no experience with working with BCs, while only $4 \%$ had extensive or considerably extensive experience.

At the same time, the respondents believed that BCs would have rather high importance in the future. Nearly half or $48 \%$, believed that BCs would have large or very large importance for the industry in general, although the importance was expected to be less for their line of business and their companies in particular. Meanwhile, 33\% believed that the importance for their companies would be large or very large, although the share of uncertain respondents was greater when it came to their own companies (Table 6).

Remarkably, however, the respondents rated the impact on their own companies as smaller, possibly indicating their positive perception of BCs but lack of immediate evidence about real-world applications. In addition, the respondents indicated that very few of their competitors, customers or suppliers work with BCT and $48 \%$ of them agreed to that claim to a very low extent (Table 7). Agreement was also low with the statements that BCT would alter their businesses and that they would lose competitive advantage if they did not begin using BCT. Even so, respondents were more certain that BCT are not mere hype and will be generally accepted in time. Respondents also strongly agreed that BCT enable new business models and new sources of income, which again showed a rather divided view amongst

Table 5.

Average knowledge and understanding of $\mathrm{BC}$ s amongst the sample's CEOs on a $1-5$ scale $(1=$ none, $5=$ a great deal)
Knowledge and

experience of $\mathrm{BCs}$

Knowledge of BCs

Experience of working with $\mathrm{BCs}$ in practice

\section{Table 6.}

Average importance of $\mathrm{BCs}$ for the future on a $1-5$ scale $(1=$ very small, $5=$ very large), excluding "I don't know"

\begin{tabular}{lcccccccc}
\hline $\begin{array}{l}\text { Importance of BCs for the } \\
\text { future for ... }\end{array}$ & $\begin{array}{c}\text { Very small } \\
(\%)\end{array}$ & $\begin{array}{c}\text { Small } \\
(\%)\end{array}$ & $\begin{array}{c}\text { Medium } \\
(\%)\end{array}$ & $\begin{array}{c}\text { Large } \\
(\%)\end{array}$ & $\begin{array}{c}\text { Very large } \\
(\%)\end{array}$ & $\begin{array}{c}\text { I donot } \\
\text { know }(\%)\end{array}$ & M & SD \\
\hline Your company & 9 & 21 & 18 & 24 & 9 & 21 & 3.0 & 1.2 \\
Your line of business & 7 & 21 & 17 & 34 & 7 & 14 & 3.2 & 1.1 \\
Industry in general & 7 & 10 & 21 & 34 & 14 & 14 & 3.4 & 1.2 \\
Society in general & 7 & 4 & 39 & 25 & 11 & 14 & 3.3 & 1.0 \\
\hline
\end{tabular}

Society in general 


\begin{tabular}{|c|c|c|c|c|c|c|c|c|}
\hline Statement & $\begin{array}{l}\text { Strongly } \\
\text { disagree }\end{array}$ & Disagree & $\begin{array}{l}\text { Neither } \\
\text { agree nor } \\
\text { disagree }\end{array}$ & Agree & $\begin{array}{c}\text { Strongly } \\
\text { agree }\end{array}$ & $\begin{array}{c}\text { I } \\
\text { donot } \\
\text { know }\end{array}$ & MSD & $\begin{array}{r}\text { of blockchain } \\
\text { technology }\end{array}$ \\
\hline \multicolumn{9}{|l|}{ Our suppliers, customers and/or } \\
\hline & 42 & 21 & 12 & 12 & 0 & 12 & 1.91 .1 & \\
\hline $\begin{array}{l}\text { BCs give us no advantages compared } \\
\text { with other current systems }\end{array}$ & 29 & 18 & 18 & 0 & 7 & 29 & 2.21 .3 & \\
\hline BCs will completely change our line of & & & & & & & & \multirow{13}{*}{$\begin{array}{r}\text { Table } 7 . \\
\text { Average agreement } \\
\text { with statements } \\
\text { regarding BCs in \% } \\
\text { on a } 1-5 \text { scale }(1= \\
\text { strongly disagree, } \\
5=\text { strongly agree) }\end{array}$} \\
\hline business & 19 & 26 & 16 & 10 & 3 & 26 & 2.31 .2 & \\
\hline BCs lower our costs & 0 & 25 & 7 & 21 & 14 & 32 & 3.41 .2 & \\
\hline $\mathrm{BCs}$ raise our business certainty & 10 & 14 & 10 & 14 & 28 & 24 & 3.51 .5 & \\
\hline BCs boost our transparency & 4 & 11 & 14 & 25 & 14 & 32 & 3.51 .2 & \\
\hline $\mathrm{BCs}$ lower our business risk & 4 & 7 & 21 & 11 & 18 & 39 & 3.51 .2 & \\
\hline BCs will eventually be widely accepted & & & & & & & & \\
\hline $\begin{array}{l}\text { and implemented } \\
\text { BCs increase our traceability in the }\end{array}$ & 0 & 3 & 32 & 26 & 19 & 19 & 3.80 .9 & \\
\hline $\begin{array}{l}\text { value chain } \\
\text { BCs are faster than other current }\end{array}$ & 4 & 11 & 18 & 14 & 36 & 18 & 3.81 .3 & \\
\hline systems & 3 & 6 & 12 & 21 & 24 & 33 & 3.91 .2 & \\
\hline BCs enable new sources of income & 0 & 10 & 21 & 17 & 31 & 21 & 3.91 .1 & \\
\hline BC-based technology is scalable & 3 & 0 & 13 & 26 & 23 & 35 & 4.01 .0 & \\
\hline $\mathrm{BC}$ s enable new business models & 3 & 0 & 19 & 19 & 39 & 19 & 4.11.1 & \\
\hline
\end{tabular}

respondents between failing to see the direct impact of BCT on their business but nevertheless perceiving the spread of $\mathrm{BCT}$ as inevitable. That picture can be strengthened by examining the different advantages that BCT is expected to afford and the generally positive view of BCs' potential benefits amongst respondents. Overall, the respondents, thus, foresaw a rather large impact from BCT but more for other companies than their own.

The respondents' uncertainties regarding $\mathrm{BCs}$ became more evident when they were asked more detailed, technical questions. For one such question regarding the level of technical security, many respondents reported that they had no understanding of the topic, whereas ones who did tend to agree with the idea that BCs offer a high level of security. By contrast, $3 \%$ stated that $\mathrm{BCs}$ are much more insecure than today's technologies, $6 \%$ that they are simply more insecure, $19 \%$ that there is no difference, $25 \%$ that they are more secure and 9\% that they are much more secure, while 38\% did not know. On the most detailed level, when asked about their understanding of technical terminology - namely, "permission-less", "private" (i.e. "permission"), "forks", "block mining”, "verified transactions", "peer-2-peer networks", "hash codes" and "hashing function", "public-key cryptography", "signature" or "signing algorithm", "race attack", "Finney attack", "majority attack" and "digital wallets" - all respondents claimed to have no knowledge.

At the company level, $9 \%$ of respondents reported that they currently used BCs, especially in free-text comments indicating that most such cases have involved tests only and that not all projects were in fact BC-based applications. Of the companies not using BCs today, $10 \%$ were discussing or planning to start BC-based projects for payments, SC-based collaboration, tracking, digital registers and/or digital currencies.

When asked what would make them implement BCT, respondents indicated that lower costs were clearly the most important factor but that the potential for new business models and, in particular, increased security and reduced risk were important as well (Table 8). 
JGOSS

Table 8.

Average rankings of factors that could make the company introduce $\mathrm{BCT}$ on a $1-5$ scale in $\%(1=$ very unimportant, 5 = very important agree)

\begin{tabular}{|c|c|c|c|c|c|c|c|}
\hline Factors & $\begin{array}{c}\text { Very } \\
\text { unimportant }\end{array}$ & Unimportant & $\begin{array}{c}\text { Neither } \\
\text { important nor } \\
\text { unimportant }\end{array}$ & Important & $\begin{array}{c}\text { Very } \\
\text { important }\end{array}$ & $\begin{array}{c}\text { I } \\
\text { donot } \\
\text { know }\end{array}$ & MSD \\
\hline \multirow{10}{*}{$\begin{array}{l}\text { If BCT gave us lower } \\
\text { costs } \\
\text { If BCT gave us better } \\
\text { business certainty } \\
\text { If BCT gave us lower } \\
\text { technical risk } \\
\text { If BCT helped us to find } \\
\text { new business models } \\
\text { If BCT gave us a lower } \\
\text { business risk } \\
\text { If BCT gave us } \\
\text { increased traceability in } \\
\text { the value chain } \\
\text { If BCT helped us to find } \\
\text { new sources of income } \\
\text { If BCT gave us } \\
\text { increased speed } \\
\text { If BCT gave us } \\
\text { increased transparency } \\
\text { There is nothing that } \\
\text { could convince us to } \\
\text { implement BCT }\end{array}$} & 0 & 0 & 21 & 21 & 29 & 29 & 4.10 .9 \\
\hline & 14 & 7 & 7 & 21 & 36 & 14 & 3.71 .6 \\
\hline & 14 & 0 & 21 & 21 & 29 & 14 & 3.61 .4 \\
\hline & 7 & 7 & 21 & 36 & 14 & 14 & 3.51 .2 \\
\hline & 7 & 0 & 36 & 29 & 14 & 14 & 3.51 .1 \\
\hline & 14 & 7 & 14 & 36 & 14 & 14 & 3.31 .4 \\
\hline & 7 & 21 & 14 & 29 & 14 & 14 & 3.31 .3 \\
\hline & 13 & 27 & 7 & 20 & 20 & 13 & 3.11 .5 \\
\hline & 21 & 0 & 36 & 14 & 14 & 14 & 3.01 .4 \\
\hline & 43 & 14 & 0 & 0 & 14 & 29 & 2.01 .6 \\
\hline
\end{tabular}

Clearly, respondents had a business-oriented perspective on BCs, which have to contribute to the company's profitability and success to gain priority. Respondents also rejected the claim that nothing could make them implement BCT, thereby displaying their willingness to adopt BCT, provided that the reasons were convincing. Even so, two of traditionally strong arguments for BCT - transparency and speed - ranked low.

Respondents also seemed to perceive several challenges with introducing BCT, the most important of which related to practical company-internal issues, including a lack of resources, that $\mathrm{BCT}$ was not a company priority and a lack of convincing applications of BCT (Table 9).

\begin{tabular}{lcccc}
\hline Factors & $\begin{array}{c}\text { Very large } \\
\text { obstacle }\end{array}$ & $\begin{array}{c}\text { Large } \\
\text { obstacle }\end{array}$ & $\begin{array}{c}\text { Small } \\
\text { Neutral obstacle obstacle }\end{array}$ & Nonow \\
\hline
\end{tabular}

Lack of relevant competence in our organisation

BCT not amongst our company's priorities

\begin{tabular}{rrrrrrr}
14 & 29 & 7 & 21 & 7 & 21 & 2.71 .3 \\
21 & 7 & 36 & 14 & 7 & 14 & 2.81 .3 \\
21 & 14 & 21 & 21 & 7 & 14 & 2.81 .4 \\
14 & 21 & 29 & 14 & 7 & 14 & 2.81 .2 \\
15 & 15 & 23 & 23 & 8 & 15 & 2.91 .3 \\
0 & 27 & 13 & 13 & 7 & 40 & 3.01 .1 \\
7 & 14 & 29 & 14 & 7 & 29 & 3.01 .2 \\
8 & 31 & 15 & 31 & 8 & 8 & 3.01 .2 \\
15 & 31 & 15 & 0 & 31 & 8 & 3.01 .6 \\
& & & & & & \\
0 & 14 & 36 & 14 & 7 & 29 & 3.20 .9 \\
\hline
\end{tabular}

\section{Table 9 .}

Average rankings of factors preventing the company from introducing BCT on a $1-5$ scale in $\%(1=$ very large obstacle, $5=$ no obstacle)
No convincing application of blockchain

Lack of internal resources

No obstacles

Legal framework

Potential security risks

Unproven technology

Concerns that the company's sensitive

information may be leaked

Implementing, replacing or adapting old

systems
Very large Large Small No I donot MSD

systems


The legal challenges surrounding BCs also appeared to be largely unknown to the respondents, with $40 \%$ of respondents selecting "I don't know". In fact, respondents seemed to be more concerned about how to use BCs and their competence in supporting them than about the technology itself. However, respondents also did not appear not to have very strong opinions about the obstacles, possibly respondents were rarely involved in BC-based projects, and thus had less knowledge about the obstacles.

\section{Discussion}

In industries around the world, businesses have recently had to consider the capability of $\mathrm{BCT}$ and its potential impacts on their businesses. In parallel, research on factors that enable or impede the adoption of BCT has expanded as well (Wang et al., 2019a).

Overall, our findings from CEOs reveal that the lower cost, traceability, improved security and trustworthiness of BCT, as well as the new business models enabled by BCs, rank amongst the key factors driving the adoption of BCT, as previously demonstrated (Hoxha and Sadiku, 2019; Queiroz et al., 2019; Saberi et al., 2019a, Sheel and Nath, 2019; Wang et al., 2019b). Sheel and Nath (2019), for example, have shown how BCs can provide a tamper-proof source of data recording and retrieval and that firms can improve the traceability of inventory items as a result. By extension, throughout SCs, the improved traceability and visibility offered by BCT can optimise the flow of information and reduce costs (Queiroz et al., 2019). Such potential has also been observed by Thomasson (2019) and Galvin (2019), who reported that BC initiatives could, for instance, be used to monitor food safety, reduce spoilage and waste and, in turn, lower operational costs and boost both trust amongst consumers and the sale of food products.

According to Wang et al. (2019b), by improving the sharing of SC-related information, $\mathrm{BCT}$ enhances the trustworthiness and security of processes and products by protecting against tampering, fraud and cybercrime, as illustrated by the BC-based initiatives of DHL and Accenture (2018) in the pharmaceutical industry. To achieve security, reliability and authenticity need to be established, both of which take the form of data integrity, a key attribute of BC-based ledgers (Yli-Huumo et al., 2016).

Although our study has identified numerous applications and advantages of BCs, adopting BCT is clearly not without challenges. Our findings suggest that one such challenge is the lack of convincing applications of BCs in familiar contexts that can help companies to reduce costs. That result corroborates past findings from Queiroz et al. (2019), Sternberg et al. (2020) and Ghode et al. (2020a), all of whom indicated a lack of successful commercial implementations of BCT. A prohibitive factor may be that the successful implementation of $\mathrm{BC}$ s requires collaboration amongst all stakeholders, who may be based in different locations, and thus subject to different jurisdictions. As Casey and Wong (2017) have stated, such complexity in operating environments hinders the smooth implementation of BCT in SC processes.

The lack of resources is another important factor that impedes the adoption of BCT. Tapscott and Tapscott (2016), as well as Wang et al. (2017) have found that adopting BCT requires financial, human and logistical resources to conduct feasibility studies and invest in relevant software and hardware. In particular, small and medium-sized companies may find it more difficult to join a $\mathrm{BC}$ platform due to financial limitations. In line with Prasad et al. (2018), we found that a lack of relevant competence in organisations discourages the adoption of BCT. Limited technical expertise and knowledge about using BCT bar the adoption of such new technology (Mougayarm, 2016). Our results additionally support research by Kembro et al. (2014) concerning how the leakage of sensitive corporate information to competitors due to the openness of $\mathrm{BC}$ platforms may hinder the adoption of 
BCT. Therefore, reluctance to revealing critical information with other SC partners may hinder the successful implementation of BCT.

Last, similar to the past research (Beck et al., 2018; Ghode et al., 2020b, Grant and Hogan, 2015; Mougayarm, 2016), legal regulations were regarded as a challenge in BCT adoption by the CEOs in our study. This is evident from contradictions in policies issued by different governments about Bitcoin that have raised concerns amongst organisations and markets around the world, which can eventually affect the broader use of BCs amongst businesses and SC networks (Mougayarm, 2016). Although currently regulations regarding BCT are unclear but businesses being built on $\mathrm{BC}$ platforms may face new regulatory challenges once country-wide regulations are adopted (Beck et al., 2018; Grant and Hogan, 2015).

\section{Conclusions}

$\mathrm{BCs}$ represent a relatively new technology that is nevertheless relatively well-known because of its commercial application in Bitcoin. However, by offering a digitalised, distributed database, the technology provides a wider spectrum of applications to actors involved and promises to be impenetrable to hackers because of cryptography and distributed databases.

In this article, we set out to study whether BCT is understood and applied in exportoriented industries, with a focus on CEOs in export-intensive companies in West Sweden. Our results showed a generally low level of adoption and few initiatives and implementations concerning BCT. Although BCT does not seem to be widely used at present, companies clearly see its potential in the future and appear to have faith in it. Perhaps, most notably, our study contributes top-level management's perspective on adopting BCT, which highlights the importance a business-oriented rationale as an overarching priority of CEOs.

To facilitate BC-based advantages such as lower costs, increased traceability, new sources of income increased security and procedural efficiency, managers should craft strategies to overcome the risks and challenges associated with adopting BCT identified in our study. We found that despite practitioners' positive impressions of BCT, they perceived difficulties with implementing it and struggled to recognise its impact on their respective businesses. Our results also reveal similar patterns in the integration of processes and the lack of certainty surrounding the cost-benefit ratios that van Hoek (2019b) observed. Beyond that, they align well with findings of how heavily hyped technologies are usually received. According to the stages of the Gartner hype curve (Gartner, 2018), new technologies are subject to a so-called "peak of inflated expectations", at which they are expected to change the world, followed by a "trough of disillusionment", at which great expectations are not fulfilled. In time, a "slope of enlightenment" occurs, when the technology finds productive space before achieving a "plateau of productivity". Although BCT began creating significant hype in late 2017, its attraction has recently declined. A survey amongst Swedish IT-consultant recently revealed that none of the firms ranked BCT as a "hot" field (Malmqvist, 2020). That trend was reflected by our respondents who, despite not considering BCs to be hype, struggle to imagine the productive use of BCT. Such patterns put $\mathrm{BCT}$ on a downward slope following its initial hype. Despite retaining some key elements of hype, its real practical uses are being increasingly questioned.

This article's valuable insights are not without limitations including a low response rate preventing more sophisticated statistical analyses. Moreover, respondents represented multiple industries, but in practice, each industry has unique needs that promote different strategic choices. For that reason, the types of perceived advantages and challenges of implementing BCT may have also varied across industries. In response, it is imperative to develop different applications for different SCs according to their needs and to test different adoption models. Industry-specific surveys about 
adopting BCs may also generate different results and, in that case, be useful to industry-specific managers and researchers. Finally, respondents' answers were based on their subjective understanding of $\mathrm{BC}$ and $\mathrm{BCT}$, which in most cases did not include any actual practical experience. In the future, qualitative studies and in-depth interviews of managers who have implemented BCT in their companies and have practical experience could provide more in-depth insights regarding top-level management's understanding of $\mathrm{BCs}$ and $\mathrm{BCT}$.

\section{Acknowledgement}

Authors wish to thanks the West Sweden Chamber of Commerce for its cooperation in distributing the survey and Árni Halldórsson comments on the early versions of the paper. The project was funded by the Strategic Research Area Transport, a research programme at the University of Gothenburg and Chalmers University of Technology.

\section{Note}

1. In the statutes of the WSCC, West Sweden is defined as the county of Västra Götaland and the municipalities of Kungsbacka and Varberg. Although no exact account of the number of exportoriented firms in the area exists, the total number of firms with a turnover of more than $20 \mathrm{~m}$ SEK (approximately $€ 2 \mathrm{~m}$ ) is 8,200. In Sweden overall, $15 \%$ of the total number of firms or 1230 firms, are considered to be export-oriented; see Tillväxtverket (2018). Thus, the target sample included the vast majority of export-oriented firms in West Sweden.

\section{References}

Åhlström, P. and Westbrook, R. (1999), "Implications of mass customization for operations management", International Journal of Operations and Production Management, Vol. 19 No. 3, pp. 262-275.

Akins, B.W., Chapman, J.L. and Gordon, J.M. (2015), “A whole new world: income tax considerations of the bitcoin economy", Pittsburgh Tax Review, Vol. 12 No. 1, pp. 24-56.

Androulaki, E., Barger, A., Bortnikov, V., Cachin, C., Christidis, K., Caro, A.D., Enyeart, D., Ferris, C., Laventman, G., Manevich, Y., Muralidharan, S., Murthy, C., Nguyen, B., Sethi, M., Singh, G., Smith, K., Sorniotti, A., Stathakopoulou, C., Vukolić, M., Cocco, S.W. and Yellick, J. (2018), "Hyperledger fabric: a distributed operating system for permissioned blockchains", paper presented at Proceedings of the 13th EuroSys Conference, 23-26 April, Porto, Portugal, doi: 10.1145/3190508.3190538 (accessed 13 December 2020).

Apte, S. and Petrovsky, N. (2016), "Will blockchain technology revolutionize excipient supply chain management?", Journal of Excipients and Food Chemicals, Vol. 7 No. 3, pp. 76-78.

Bag, S., Viktorovich Dmitriev, A., Sahu Atul, K. and Sahu Anoop, K. (2020), "Barriers to adoption of blockchain technology in green supply chain management", Journal of Global Operations and Strategic Sourcing.

Beck, R., Müller-Bloch, C. and King, J. (2018), "Governance in the blockchain economy: a framework and research agenda", Journal of the Association for Information Systems, Vol. 19 No. 10, pp. 1020-1034.

Benchoufi, M., Porcher, R. and Ravaud, P. (2017), "Blockchain protocols in clinical trials: transparency and traceability of consent", F1000Research, Vol. 6, p. 66.

Benton, M.C., Radziwill, N.M., Purritano, A.W. and Gerhart, C.J. (2018), "Blockchain for supply chain: improving transparency and efficiency simultaneously", Software Quality Professional, Vol. 20 No. 3, pp. 28-38. 
Biswas, B. and Gupta, R. (2019), "Analysis of barriers to implement blockchain in industry and service sectors", Computers and Industrial Engineering, Vol. 136, pp. 225-241.

Boucher, P., Nascimento, S. and Kritikos, M. (2017), How Blockchain Technology Could Change Our Lives, European parliamentary research service, Brussels.

Boukis, A. (2019), "Exploring the implications of blockchain technology for brand-consumer relationships: a future research agenda", Journal of Product and Brand Management, Vol. 29 No. 3, pp. 307-320.

Büyüközkan, G. and Göçer, F. (2018), "Digital supply chain: literature review and a proposed framework for future research", Computers in Industry, Vol. 97, pp. 157-177.

Casey, M.J. and Wong, P. (2017), "Global supply chains are about to get better, thanks to blockchain", Harvard Business Review, available at: https://hbr.org/2017/03/global-supply-chains-are-aboutto-get-better-thanks-to-blockchain

Casino, F., Dasaklis, T.K. and Patsakis, C. (2019), "A systematic literature review of blockchain-based applications: current status, classification and open issues", Telematics and Informatics, Vol. 36, pp. $55-81$.

Christopher, M. (2011), Logistics and Supply Chain Management: creating Value-Adding Networks, 4th ed., Prentice Hall, New York, NY.

Collomb, A. and Sok, K. (2016), "Blockchain/distributed ledger technology (DLT): what impact on the financial sector?", Communications and Strategies, Vol. 3 No. 103, pp. 93-111.

Cooper, D. and Nash, G. (2000), "Blockchain and privacy", in Madir, J. (Ed.) Fintech: Law and Regulation, Elgar Financial Law and Practice, Cheltenham, pp. 232-253.

Croman, K., Decker, C., Eyal, I., Gencer, A.E., Juels, A., Kosba, A. and Song, D. (2016), “On scaling decentralized blockchains", in the international conference on financial cryptography and data security, pp. 106-125.

Crosby, M., Nachiappan, Pattanayak, P., Verma, S. and Kalyanaraman, V. (2016), "Blockchain technology: beyond bitcoin”, Applied Innovation Review (AIR), Vol. 6 No. 2, pp. 6-10.

Daimler (2020), "Once round the block, please!”, available at: www.daimler.com/innovation/blockchain2.html (accessed 4 December 2020).

Dhillon, V., Metcalf, D. and Hooper, M. (2017), Blockchain Enabled Applications: Understand the Blockchain Ecosystem and How to Make It Work for You, Apress, Secaucus, NJ.

DHL and Accenture (2018), "DHL and accenture unlock the power of blockchain in logistics", available at: https://newsroom.accenture.com/news/dhl-and-accenture-unlock-the-power-of-blockchain-inlogistics.htm (accessed 4 December 2020).

Dobrovnik, M., Herold, D., Fürst, E. and Kummer, S. (2018), "Blockchain for and in logistics: What to adopt and where to start", Logistics, Vol. 2 No. 3, pp. 1-14.

Durach, C.F., Blesik, T., von Düring, M. and Bick, M. (2020), "Blockchain applications in supply chain transactions", Journal of Business Logistics, pp. 1-18.

Everledger (2020), "Insights”, available at: www.everledger.io/insights/ (accessed 4 December 2020).

Feng, T. (2017), "A supply chain traceability system for food safety based on HACCP, blockchain and internet of things", in 2017 International Conference on Service Systems and Service Management, Dalian, 16-18June 2017, pp. 1-6.

Francisco, K. and Swanson, D. (2018), "The supply chain has no clothes: technology adoption of blockchain for supply chain transparency", Logistics, Vol. 2 No. 1.

Fui-Hoon Nah, F., Lee-Shang Lau, J. and Kuang, J. (2001), "Critical factors for successful implementation of enterprise systems", Business Process Management Journal, Vol. 7 No. 3, pp. 285-296.

Galvin, D. (2019), "IBM and walmart: blockchain for food safety", available at: www-01.ibm.com/ events/wwe/grp/grp308.nsf/vLookupPDFs/6\%20Using \%20Blockchain \%20for \%20Food \% 
20Safe $\% 202 / \$$ file $/ 6 \% 20$ Using $\% 20$ Blockchain $\% 20$ for $\% 20$ Food $\% 20$ Safe $\% 202 . p d f$ (accessed 6 April 2020).

Ganne, E. (2018), Can Blockchain Revolutionize International Trade?, WTO Publications, World Trade Organization WTO, Geneva.

Understanding of blockchain technology

Gartner (2018), "Understanding gartner's hype cycles”, available at: www.gartner.com/en/documents/ 3887767 (accessed 4 December 2020).

Gausdal, A., Czachorowski, K. and Solesvik, M. (2018), “Applying blockchain technology: evidence from norwegian companies”, Sustainability, Vol. 10 No. 6, pp. 1-16.

Ghode, D., Jivanrao, Y., Vinod, J. and Rakes, S.G. (2020a), "Blockchain adoption in the supply chain: an appraisal on challenges", Journal of Manufacturing Technology Management, Vol. 32 No. 1.

Ghode, D., Yadav, V., Jain, R. and Soni, G. (2020b), “Adoption of blockchain in supply chain: an analysis of influencing factors", Journal of Enterprise Information Management, Vol. 33 No. 3, pp. 437-456.

Grant, G. and Hogan, R. (2015), "Bitcoin: risks and controls", Journal of Corporate Accounting and Finance, Vol. 26 No. 5, pp. 29-35.

Gupta, M. (2018), Blockchain for Dummies IBM Limited Edition, John Wiley and Sons, Hoboken, NJ.

Gürdür, D., El-Khoury, J. and Törngren, M. (2019), "Digitalizing swedish industry: What is next?: data analytics readiness assessment of swedish industry, according to survey results", Computers in Industry, Vol. 105, pp. 153-163.

Hackius, N. and Petersen, M. (2017), "Blockchain in logistics and supply chain: trick or treat?", paper presented at Hamburg International Conference of Logistics, 12-14 October, Hamburg, available at: www.econstor.eu/bitstream/10419/209299/1/hicl-2017-23-003.pdf (accessed 7 December 2020).

Haraldson, S., Lind, M., Karlsson, M., Bach, A., Woxenius, J. and Gonzalez-Aregall, M. (2020), Digitalisation and automation in small and medium sized Swedish ports (SMPs), Lighthouse Reports, Lighthouse Competence Centre, Gothenburg.

Heutger, M. and Kückelhaus, M. (2018), Blockchain in Logistics: Perspectives on the Upcoming Impact of Blockchain Technology and Use Cases for the Logistics Industry, DHL Customer Solutions and Innovation.

Hoxha, V. and Sadiku, S. (2019), "Study of factors influencing the decision to adopt the blockchain technology in real estate transactions in Kosovo", Property Management, Vol. 37 No. 5, pp. 684-700.

Hwang, J., Choi, M-I., Lee, T., Jeon, S., Kim, S., Park, S. and Park, S. (2017), "Energy prosumer business model using blockchain system to ensure transparency and safety", Energy Procedia, Vol. 141, pp. 194-198.

Kembro, J., Selviaridis, K. and Näslund, D. (2014), "Theoretical perspectives on information sharing in supply chains: a systematic literature review and conceptual framework", Supply Chain Management: An International Journal, Vol. 19 No. 5/6, pp. 609-625.

Khatri, Y. (2018), "Blockchain oil trading platform backed by shell and BP is now live", available at: www.dhl.com/global-en/home/insights-and-innovation/insights/blockchain.html (accessed 4 December 2020).

Ko, T., Lee, J. and Ryu, D. (2018), "Blockchain technology and manufacturing industry: real-Time transparency and cost savings", Sustainability, Vol. 10 No. 11, pp. 1-20.

Korpela, K., Hallikas, J. and Dahlberg, T. (2017), "Digital supply chain transformation toward blockchain integration", in Proceedings of the 50 th HI international conference on system sciences.

Krombholz, K., Judmayer, A., Gusenbauer, M. and Weippl, E. (2017), "The other side of the coin: user experiences with bitcoin security and privacy", in Grossklags, J.P.B. (Ed.) Financial Cryptography and Data Security. FC 2016. Lecture Notes in Computer Science, Springer, Berlin, pp. $555-580$. 
Kshetri, N. (2018), "Blockchain's roles in meeting key supply chain management objectives", International Journal of Information Management, Vol. 39, pp. 80-89.

Lim, I.K., Kim, Y.H., Lee, J.G., Lee, J.P., Nam-Gung, H. and Lee, J.K. (2014), "The analysis and countermeasures on security breach of bitcoin", in Murgante, B. (Ed.) Computational Science and Its Applications - ICCSA 2014, Springer, pp. 720-732.

McKenzie, J. (2018), “Why blockchain won’t fix food safety - yet”, available at: https://thecounter.org/ blockchain-food-traceability-walmart-ibm/ (accessed 4 December 2020).

Madir, J. (2000), "Smart contracts", in Madir, J. (Ed.) Fintech: Law and Regulation, Elgar Financial Law and Practice, Cheltenham, pp. 148-170.

Maersk (2019), "Maersk and IBM introduce TradeLens blockchain shipping solution", available at: www.maersk.com/news/2018/06/29/maersk-and-ibm-introduce-tradelens-blockchain-shippingsolution (accessed 30 September 2019).

Malmqvist, M. (2020), "Hajpade tekniken som ingen vill använda - blockkedjan iskall bland konsultbolagen (the hyped technology that noone wants to use - blockchain ice cold among consulting firms)", Computer Sweden, 2020-12-07.

Michelman, P. (2017), "Seeing beyond the blockchain hype", MIT Sloan Management Review, Vol. 58 No. 4, pp. 1-17.

Morabito, V. (2017), Business Innovation through Blockchain: The B3 Perspective, Springer Nature, Cham.

Morkunas, V.J., Paschen, J. and Boon, E. (2019), "How blockchain technologies impact your business model”, Business Horizons, Vol. 62 No. 3, pp. 295-306.

Mougayarm, W. (2016), The Business Blockchain: Promise, Practice, and Application of the Next Internet Technology, Wiley.

OECD (2018), OECD Reviews of Digital Transformation: Going Digital in Sweden, OECD Publishing, Paris.

Oke, A. (2004), "Barriers to innovation management in service companies", Journal of Change Management, Vol. 4 No. 1, pp. 31-44.

Patel, D., Bothra, J. and Patel, V. (2017), "Blockchain exhumed”, in Asia Security and Privacy (ISEASP) conference, Surat, 29 January-1 February, pp. 1-12.

Petersen, M., Hackius, N. and Von See, B. (2018), "Mapping the sea of opportunities: blockchain in supply chain and logistics", it - Information Technology, Vol. 60 Nos 5/6, pp. 263-271.

Prasad, S., Shankar, R., Gupta, R. and Roy, S. (2018), "A TISM modeling of critical success factors of blockchain based cloud services", Journal of Advances in Management Research, Vol. 15 No. 4, pp. 434-456.

Provenance (2019), "From shore to plate: tracking tuna on the blockchain", available at: www. provenance.org/tracking-tuna-on-the-blockchain (accessed 4 December 2020).

Queiroz, M.M., Telles, R. and Bonilla, S.H. (2019), "Blockchain and supply chain management integration: a systematic review of the literature", Supply Chain Management: An International Journal, Vol. 25 No. 2, pp. 241-254.

Risius, M. (2017), “A blockchain research framework what we (don’t) know, where we go from here, and how we will get there", Business and Information Systems Engineering, Vol. 59 No. 6.

Ryan, P. (2017), "Smart contract relations in e-Commerce: legal implications of exchanges conducted on the blockchain", Technology Innovation Management Review, Vol. 7 No. 10, pp. 14-21.

Saberi, S., Kouhizadeh, M. and Sarkis, J. (2019a), "Blockchains and the supply chain: findings from a broad study of practitioners", IEEE Engineering Management Review, Vol. 47 No. 3, pp. 95-103.

Saberi, S., Kouhizadeh, M., Sarkis, J. and Shen, L. (2019b), "Blockchain technology and its relationships to sustainable supply chain management", International Journal of Production Research, Vol. 57 No. 7, pp. 2117-2135. 
Saveen, A. and Radmehr, M. (2016), "Blockchain ready manufacturing supply chain using distributed ledger", International Journal of Research in Engineering and Technology, Vol. 50 No. 9, pp. 1-10.

Sheel, A. and Nath, V. (2019), "Effect of blockchain technology adoption on supply chain adaptability, agility, alignment and performance", Management Research Review, Vol. 42 No. 12, pp. 1353-1374.

Sternberg, H.S., Hofmann, E. and Roeck, D. (2020), "The struggle is real: insights from a supply chain blockchain case", Journal of Business Logistics, pp. 1-17.

Tapscott, D. and Tapscott, A. (2016), "How blockchain will change organizations", MIT Sloan Management Review, Vol. 58 No. 2, pp. 1-4.

Thomasson, E. (2019), "Carrefour says blockchain tracking boosting sales of some products", available at: https://uk.reuters.com/article/us-carrefour-blockchain/carrefour-says-blockchain-trackingboosting-sales-of-some-products-idUKKCN1T42A5?rpc $=401 \&$ (accessed 4 December 2020).

Tillväxtverket (2018), "Fler företag blir internationella (more firms get international)", available at: https://tillvaxtverket.se/statistik/vara-undersokningar/resultat-fovven-2017/2018-11-23-flerforetag-blir-internationella.html (accessed 4 December 2020).

UN-ECE (2019), Blockchain in Trade Facilitation: Sectoral Challenges and Examples, United Nations Economic Commission for Europe, Geneva.

VAKT (2020), "Post trade management platform", available at: www.vakt.com/ (accessed 4 December 2020).

van Hoek, R. (2019a), "Developing a framework for considering blockchain pilots in the supply chain lessons from early industry adopters", Supply Chain Management: An International Journal, Vol. 25 No. 1, pp. 115-121.

van Hoek, R. (2019b), "Unblocking the chain - findings from an executive workshop on blockchain in the supply chain”, Supply Chain Management: An International Journal, Vol. 25 No. 2, pp. 255-261.

Wamba, S.F. and Queiroz, M.M. (2020), "Blockchain in the operations and supply chain management: benefits, challenges and future research opportunities", International Journal of Information Management, Vol. 52, pp. 1-9.

Wang, Y., Han, J.H. and Beynon-Davies, P. (2019a), "Understanding blockchain technology for future supply chains: a systematic literature review and research agenda", Supply Chain Management: An International Journal, Vol. 24 No. 1, pp. 62-84.

Wang, Y., Singgih, M., Wang, J. and Rit, M. (2019b), "Making sense of blockchain technology: How will it transform supply chains?", International Journal of Production Economics, Vol. 211, pp. 221-236.

Wang, J., Wu, P., Wang, X. and Shou, W. (2017), "The outlook of blockchain technology for construction engineering management", Frontiers of Engineering Management, Vol. 4 No. 1, pp. 67-75.

Wüst, K. and Gervais, A. (2018), "Do you need a blockchain?”, paper presented at 2018 Crypto Valley Conference on Blockchain Technology (CVCBT), 20-22 June, Zug, Switzerland. (accessed 13 December 2020).

Yaga, D., Mell, P., Roby, N. and Scarfone, K. (2019), Blockchain Technology Overview, National Institute of Standards and Technology, US Department of Commerce, Gaithersburg, MD.

Yang, C.S. (2019), "Maritime shipping digitalization: blockchain-based technology applications, future improvements, and intention to use", Transportation Research Part E: Logistics and Transportation Review, Vol. 131, pp. 108-117.

Yli-Huumo, J., Ko, D., Choi, S., Park, S. and Smolander, K. (2016), "Where is current research on blockchain technology? - a systematic review", Plos One, Vol. 11 No. 10. 
JGOSS

Zhao, J., Fan, S. and Yan, J. (2016), "Overview of business innovations and research opportunities in blockchain and introduction to the special issue", Financial Innovation, Vol. 2 No. 1, pp. 1-7.

Zhou, Y., Soh, Y.S., Loh, H.S. and Yuen, K.F. (2020), "The key challenges and critical success factors of blockchain implementation: policy implications for singapore's Maritime industry", Marine Policy, Vol. 122, pp. 1-10.

\section{Further reading}

Reporter, (2017), “Global supply chains are about to get better, thanks to blockchain”, Harvard Business Review, Issue 13 March.

\section{Appendix}

The survey instrument translated into English.

\section{Corresponding author}

Viktor Elliot can be contacted at: viktor.elliot@gu.se

For instructions on how to order reprints of this article, please visit our website: www.emeraldgrouppublishing.com/licensing/reprints.htm

Or contact us for further details: permissions@emeraldinsight.com 